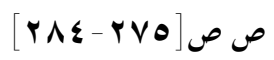

\author{
شفافية نظم المعلومات \\ (منظور استر اتيجي) \\ الدكتور مصطفى محمد صديق

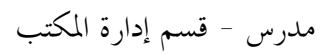

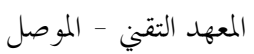

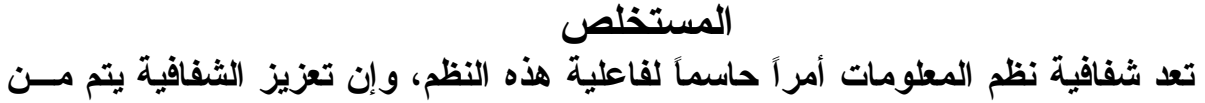

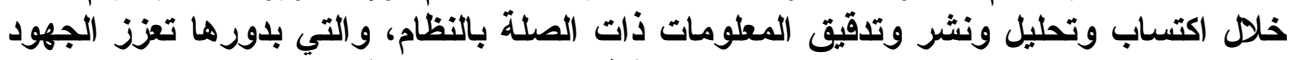

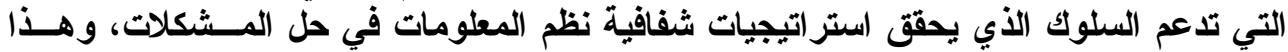

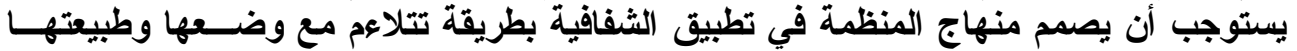

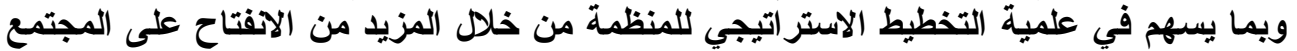

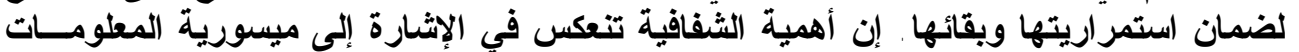

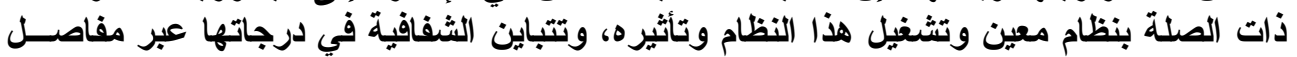

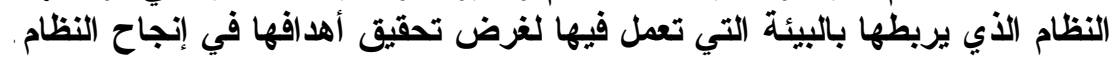

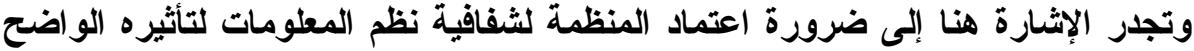

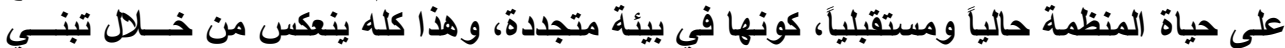

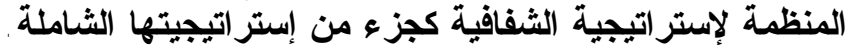

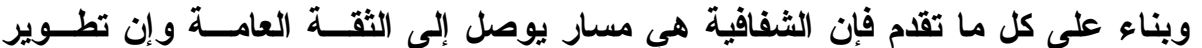

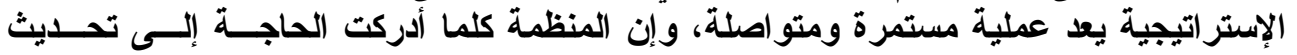

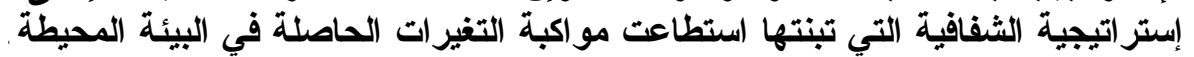

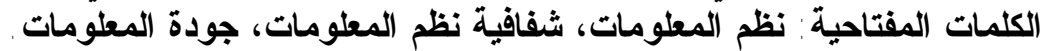

\title{
Transparency of Information Systems: A Strategic Perspective
}

\author{
Mustafa M. Saddik (PhD) \\ Lecturer \\ Department of Office Management \\ Technical Institute - Mosul
}

\section{Abstract}

Transparency of information systems is considered as a decisive issue for these systems. The enhancement of this transparency is achieved through acquiring analyzing,

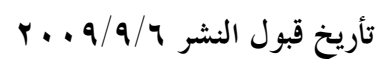

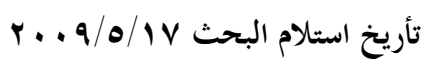


circulating and checking the information related to the system. This in turn enhances the efforts that support the behavior which achieves the strategies of transparency of information systems in solving the problems. This also requires designing the approach of the organization in applying transparency, in away that suits its condition and nature and contributes to the strategic operation of the organization through being receptive to the society to ensure its existence and continuity. The importance of transparency is reflected in signaling the availability of information related to a given organization, effort and variation the transparency in its degree throughout the parts of the organization. They connect it with the environment to achieve the organizational aims. The organization should use transparency of information systems due to its obvious influence during the current situation and future of the organization as it lives in a renewing environment.

Key words: Information system, Information system Transparency, Information Quality.

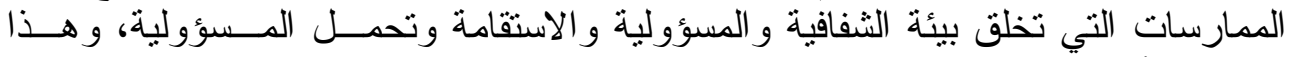

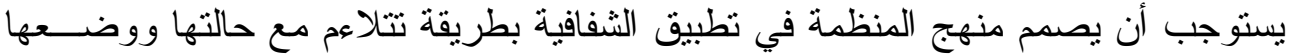

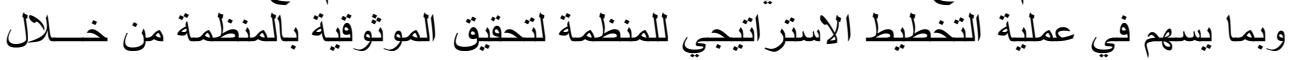

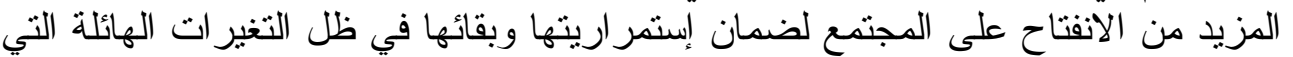

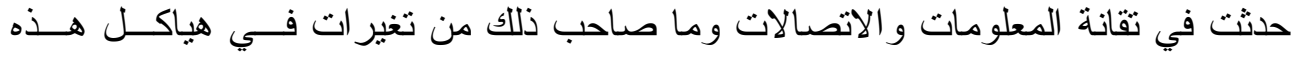

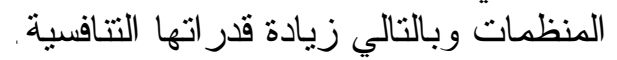

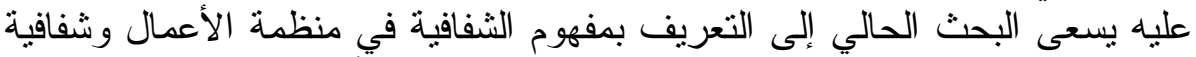

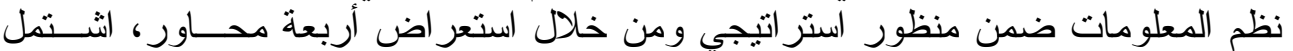

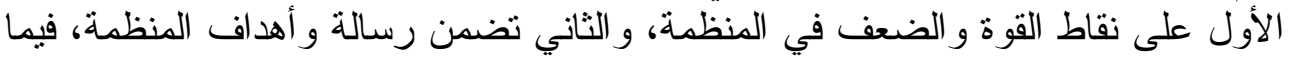

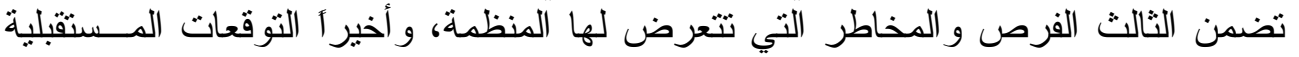

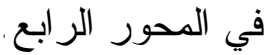

\section{منهجية البحث مشكلة البحث}

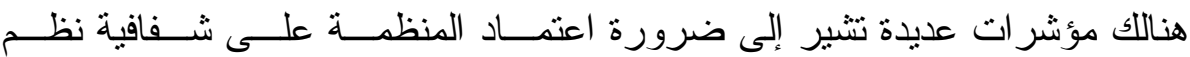

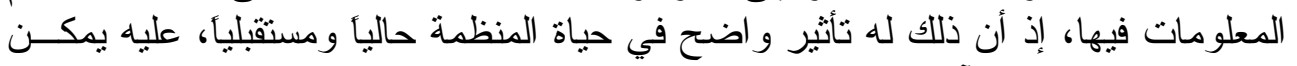

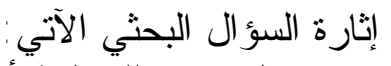

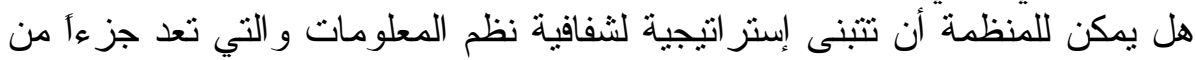

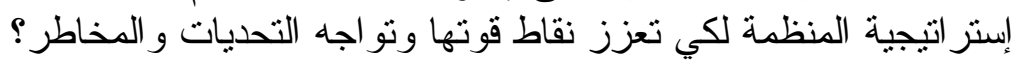

أهمية البحث وأهدافه

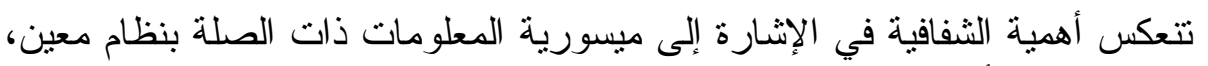

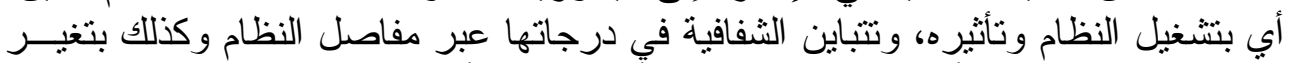

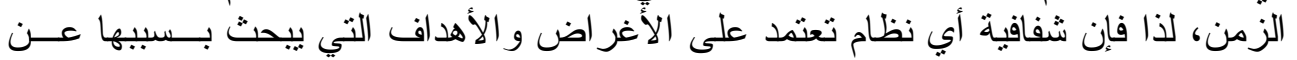

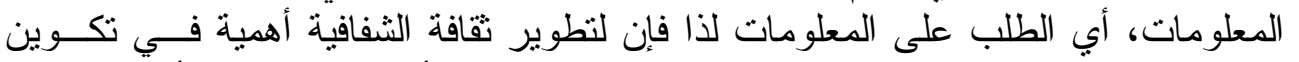

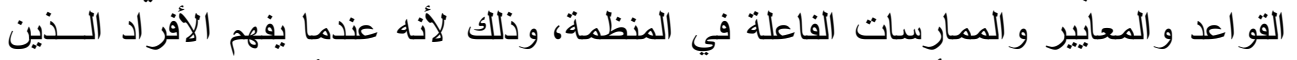
يتعاملون بها جيدأ مدى أهميتها وسبب تبنيهم لها تنز ايد لديهم النقة بأن إستر اتيجية الثفافية التهاتية 


\section{ص صديق]}

الفاعلة هي تلك التي ينت ربطها بالبيئة التي تعمل فيها وأن هذا يتجسد من خلال تحقيقهــا

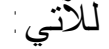
• المساهمة في زرع الإنقة و الموثوقية بالمنظمة عند الآخرين. • زيادة الفاعلية من خلال تحسين فهم المنظمة للتطبيقات الاجتماعية و البيئيـــة المحتملـــة ل ن نشاطاتها. • تحسين أداء المنظمة من خلال الدافعية في المنظمة من أجل تحقيق غاياتها المعلنة.

يمكن صياغة فرضية للبحث الحالي بهدف التوصل إلى إجابة عن السؤال المثنار آنفأ،

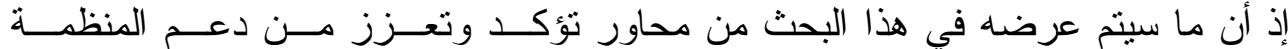

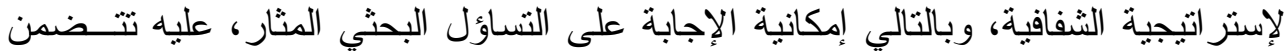

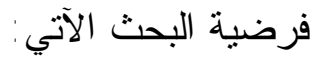

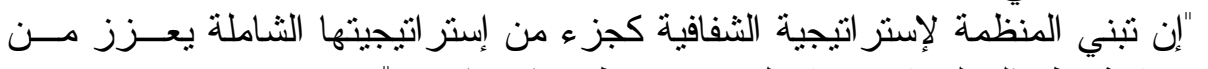
اعتماد شفافية نظم المعلومات فيها على وفق منظور استر اتيجي".

من خلال التعرف على طبيعة المشكلة و أهميتها فإن الباحث سيتتاول عـــدة محســاور

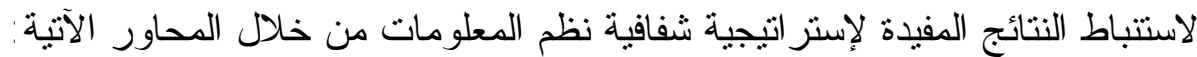
1 . نقاط القوة و الضعف للمنظمة. r r بادئ ورسالة المنظمة.

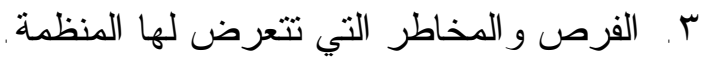
ع ـ التوقعات المستقبلية.

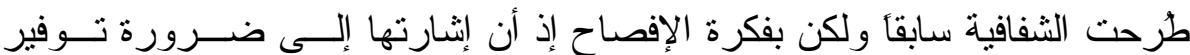

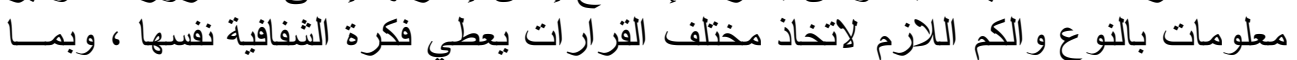

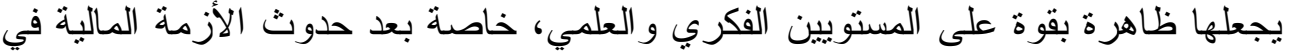

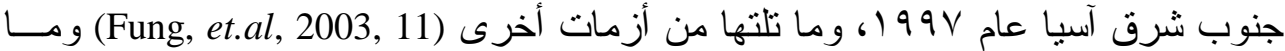

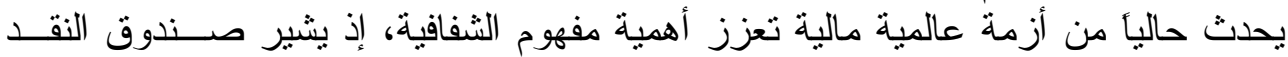

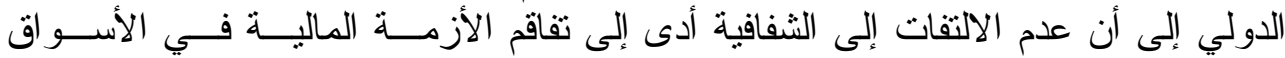

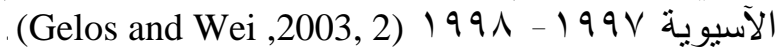

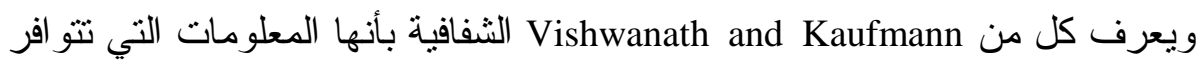

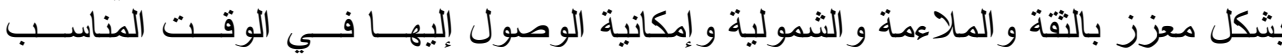
(Vishwanath and Kaufmann,1999, 3)

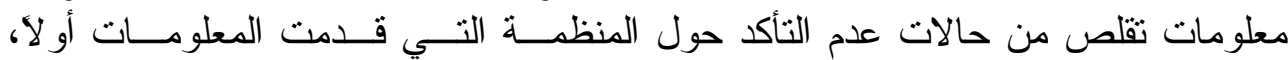

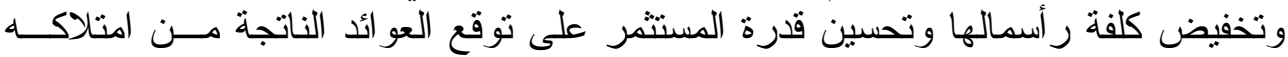


ووضعت Global Environmental Managenet Initiative) GEMI تعريفأ للشفافية على أنها انفتاح أية منظمة بالمعلومات التي تستعد للمشاركة فيها عن عملياتها التـشغيلية،

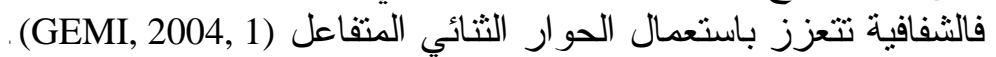
ويرى الباحث أن معظم التعاريف التي وردت عن الثفافية تشير إلى فكرة أساسـية

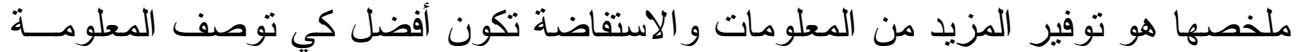

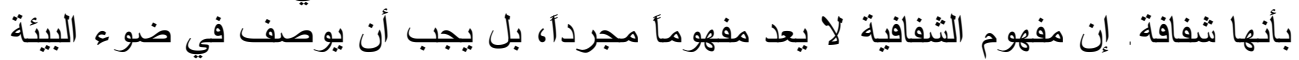
المحيطة بما تتضمنه من عناصر و أبعاد ثقافية واجتماعية وسياسية و اقتصادية وتكنلوجية.

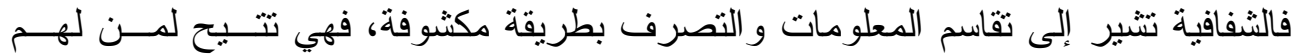

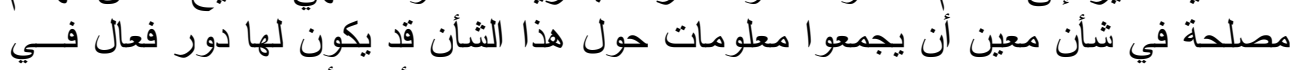

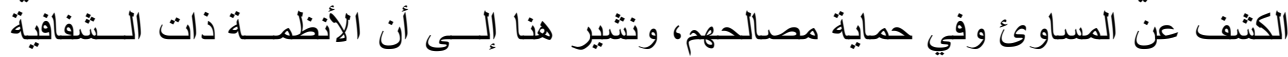

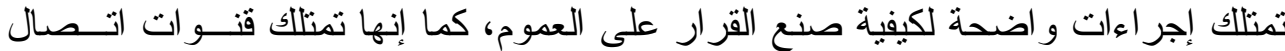

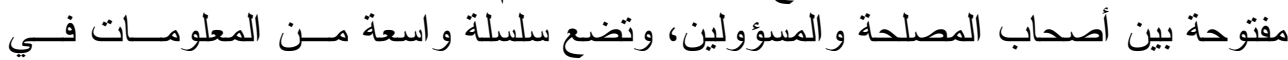

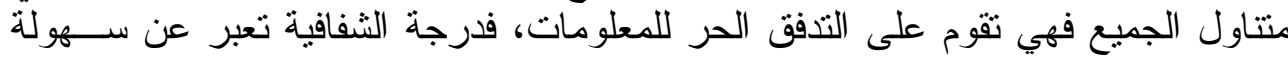
الوصول إلى المعلومات خدمة لصانع القرار أو صأف صاحب المصلحة.

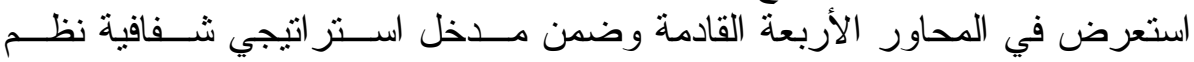

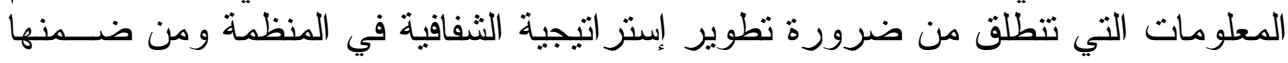

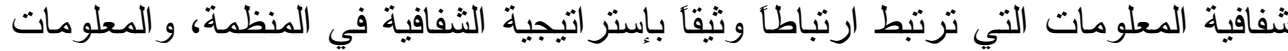

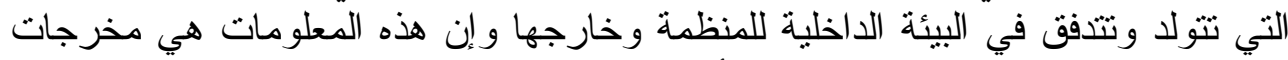

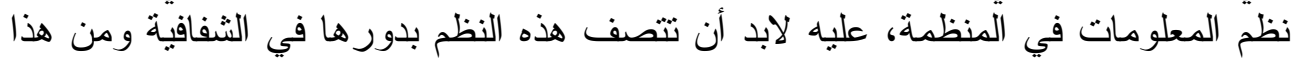

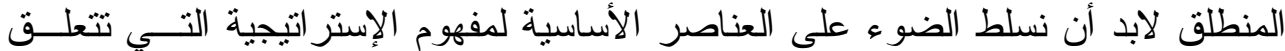
بشفافية نظم المعلومات في المحاور الأربعة القادمة.

المحور الأول - نقاط القوة والضعف للمنظمة

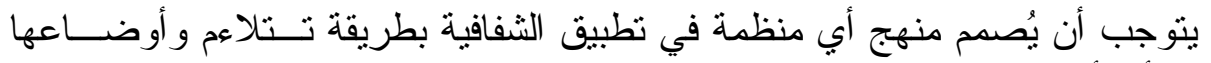

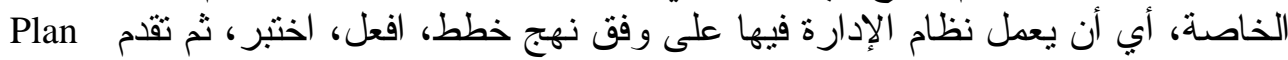
توض - Do - Check - Advance

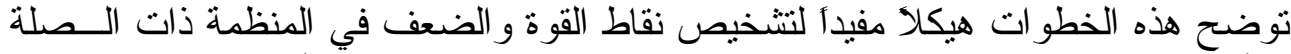

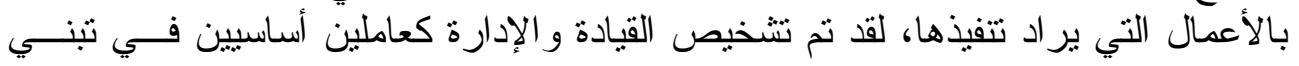

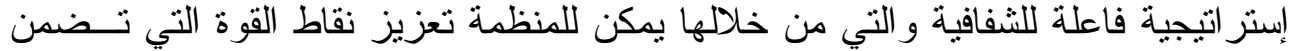

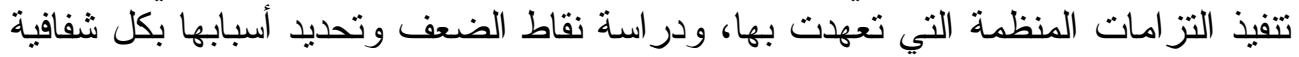

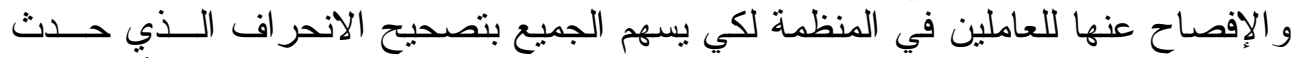

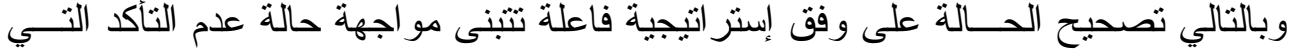

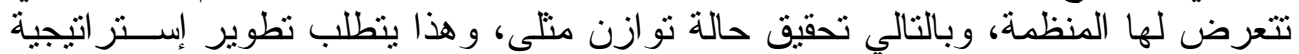
الثفافية في المنظمة لمو اجهة التحديات الآتية (GEMI,2004, 22): 1 . الموازنة بين الإفصاح و الإظهار مع الحاجة إلى السرية و أمن المعلومات.

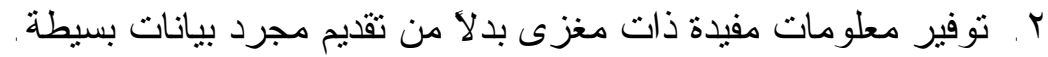

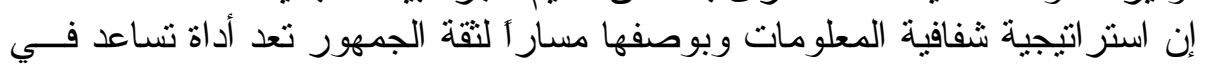

مو اجهة التحديات المذكورة آنفاً. 


\section{[rva] صديق[}

إن الثفافية تنباين في درجاتها عبر مفاصل أي نظام، وكذلك بين النظم ذاتها كمــــا تتباين بتغير الزمن، لذلك نجد أن بعض الأنظمة تكون أكثر شفافية مقارنة مع نظم أخرى،

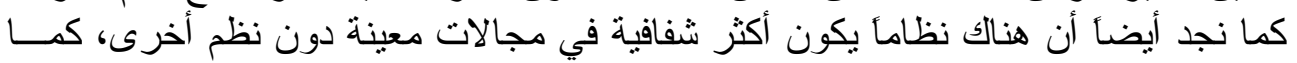

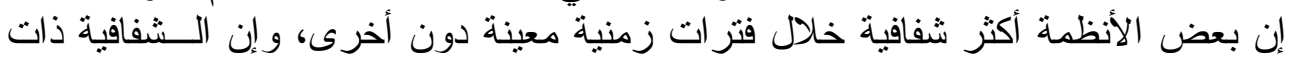

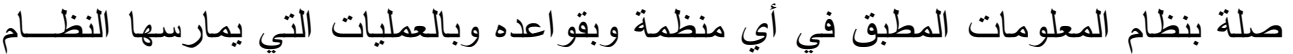

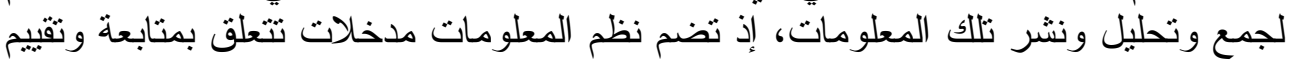

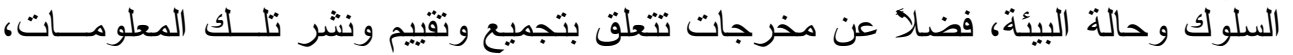

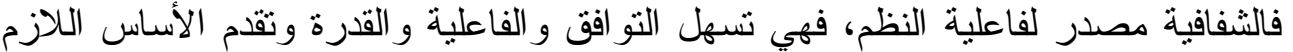
لأي نظام لفعل ما هو أفضل ولمعرفة ما يجب فعله بشكل أفضل (Ronald, 1998, 111).

المحور الثاني - رسالة وأهداف المنظمة

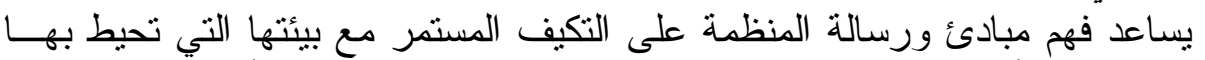

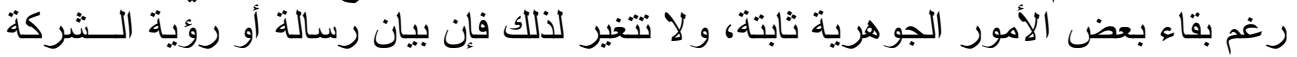

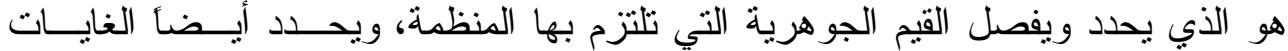

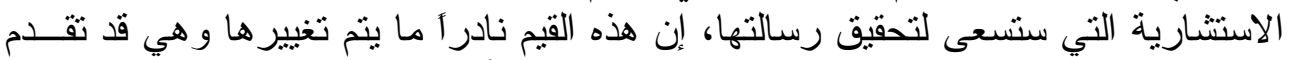

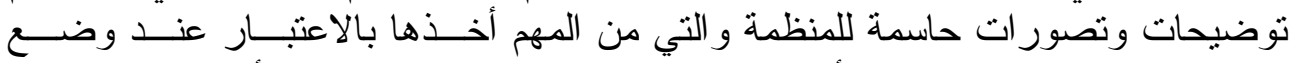

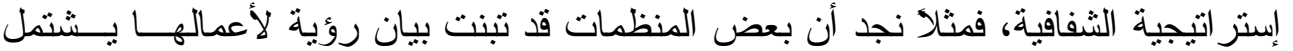

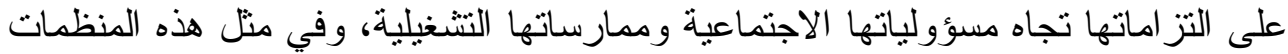

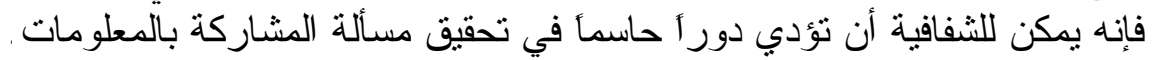

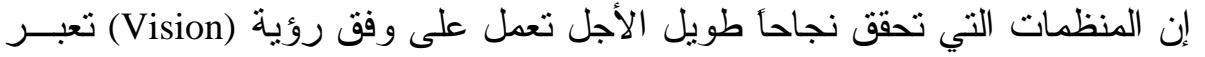

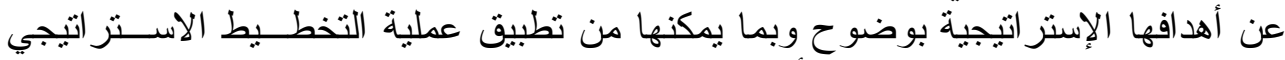

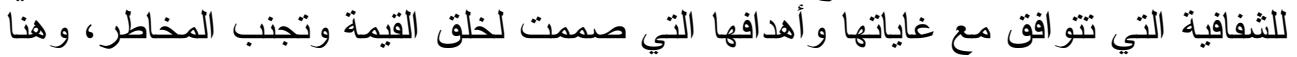

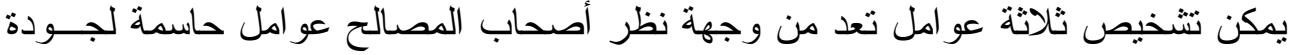

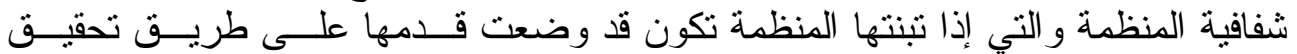

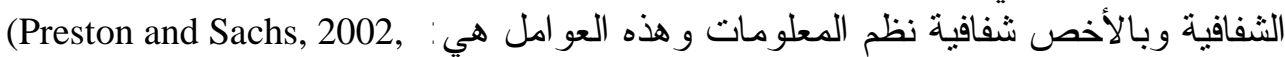

The Quality of Information بودة المعلومات

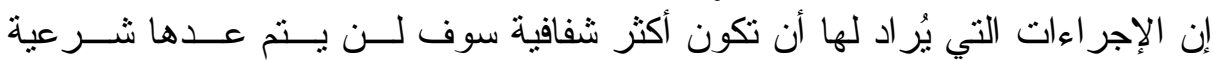

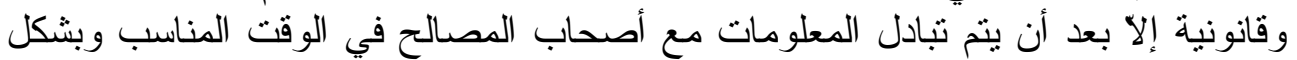

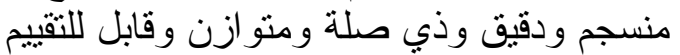

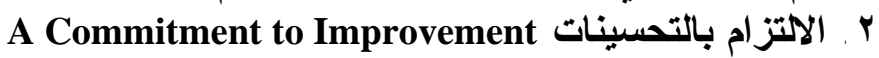

يتوجب توجيه نشاطات شفافية المنظمة باتجاه تعيين التحديات وليس تبرير مستويات

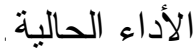

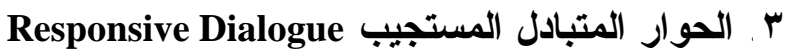

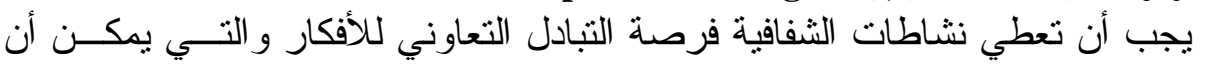

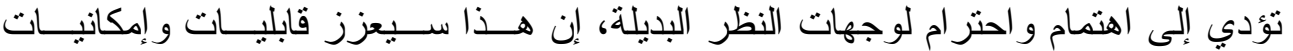

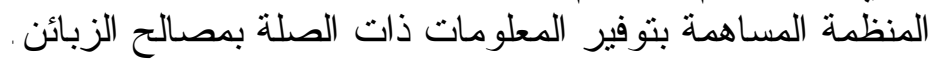




\section{المحور الثالث - الفرص والمخاطر التي تتعرض لها المنظمة}

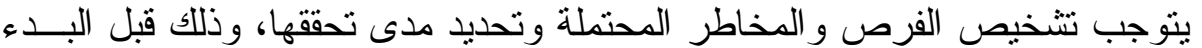

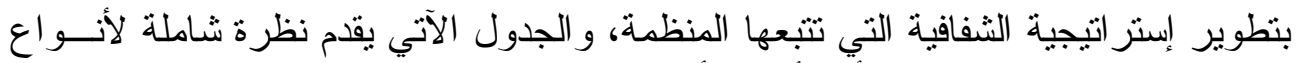

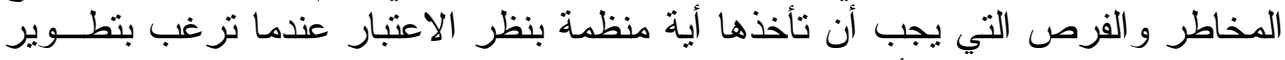

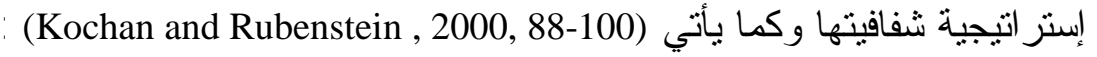

"جدول المخاطر و الفرص المرتبطة بالثفافية"

\begin{tabular}{|c|c|c|}
\hline الفرص ities & المجال المتأثّر & 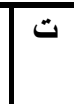 \\
\hline 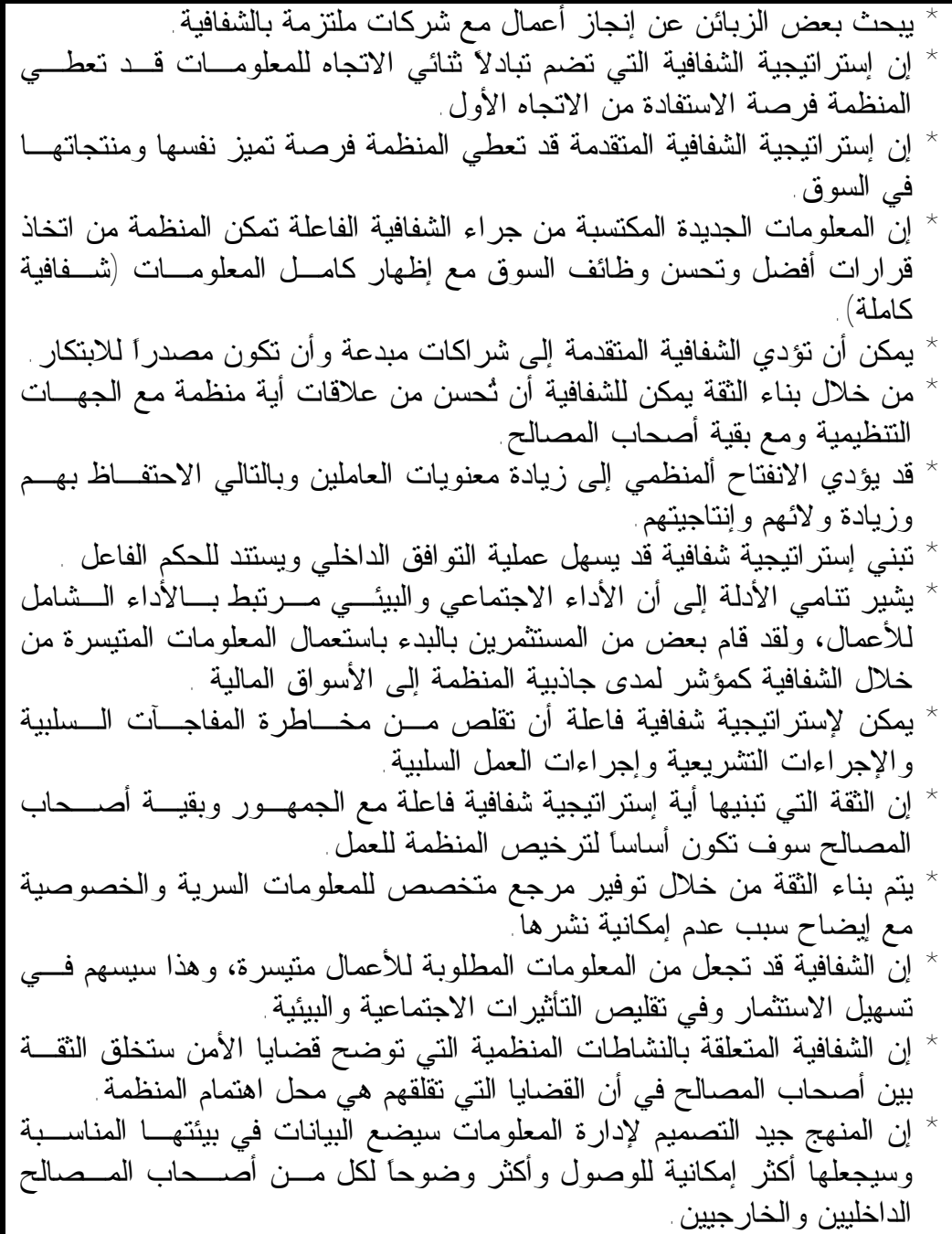 & 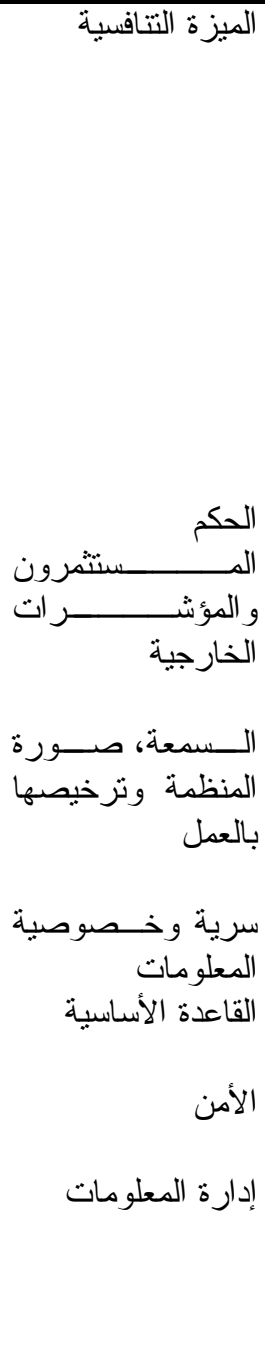 & 7 \\
\hline
\end{tabular}


Source: Kochan and Rubenstein , 2000, " Toward a Stakeholder Theory of the Firm : The Saturn Parthership, Organizational Science . 


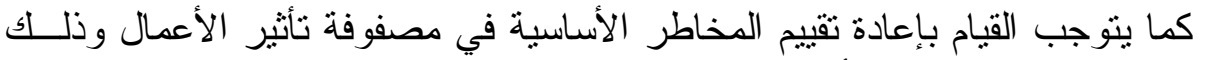
استتاداً إلى الإجابة على هذه الأسئلة:

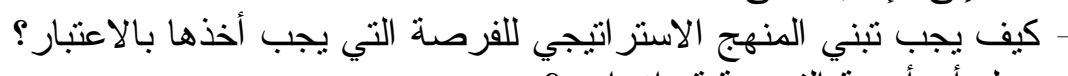

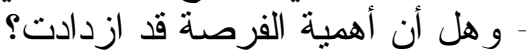

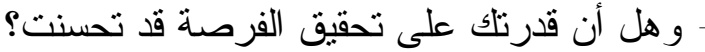

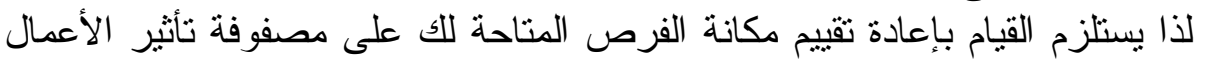
استتادَ إلى الإجابة على الأسئلة المطروحة آنفأ.

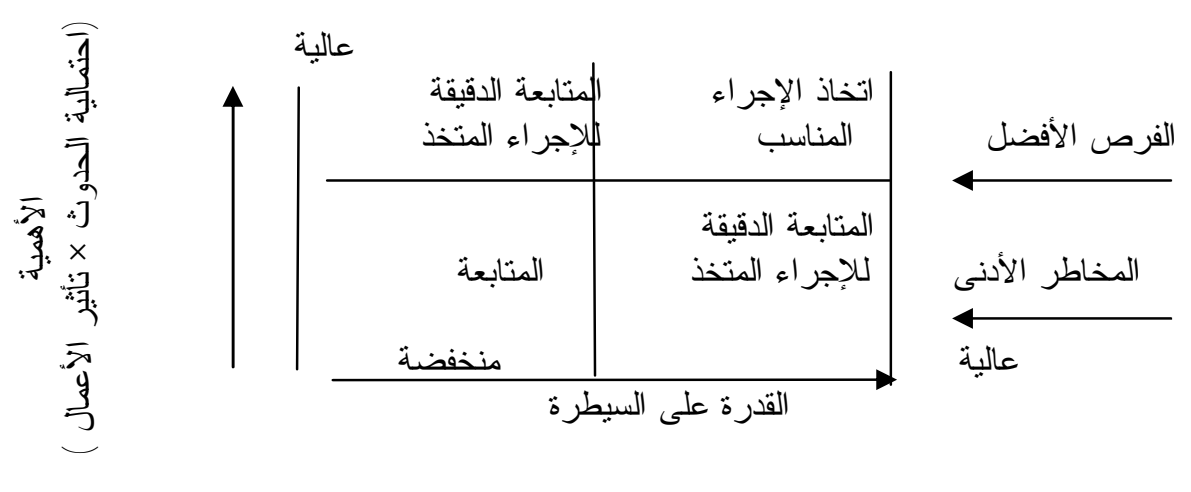

\section{شكل مصفوفة تأثثر الأعمال}

Source: Kochan and Rubenstein, 2000, " Toward a Stakeholder Theory of the Firm: The Saturn Parthership, Organizational Science .

ويرى الباحث أن اختيار المنهج الاستر اتيجي ذي القدرة الأكبر على تحويل مخاطر

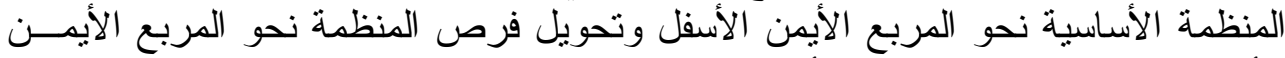

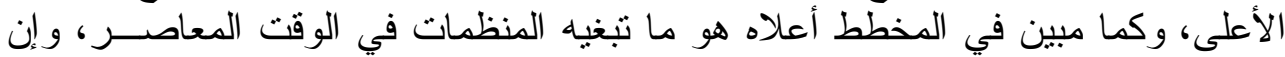

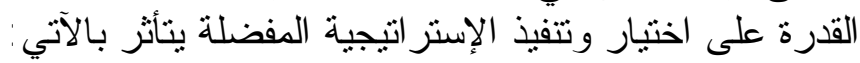

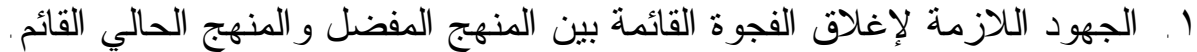

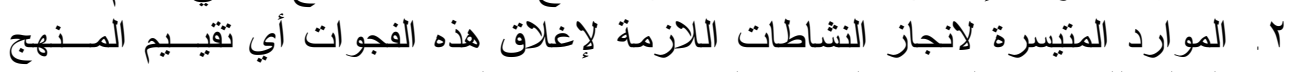
الحالي للشفافية و المو ارد المتيسرة لنتفيذ إستر اتيجية الثفافية.

\section{المحور الرابع - التوقعات المستقبلية}

في حال تبني إستر اتيجية الثفافية فإنه يجب وضعات التع الأهداف و الغايات الإستر اتيجية،

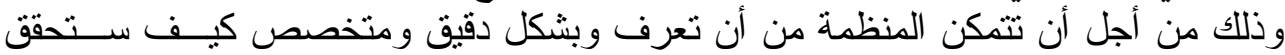

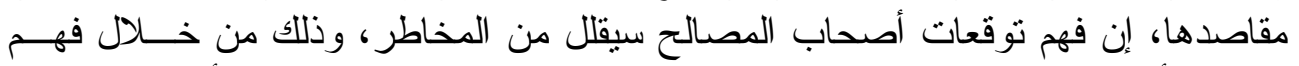

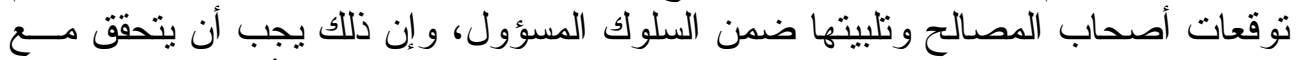

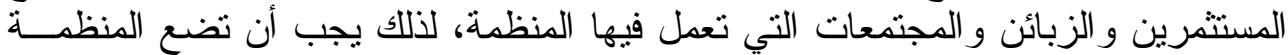

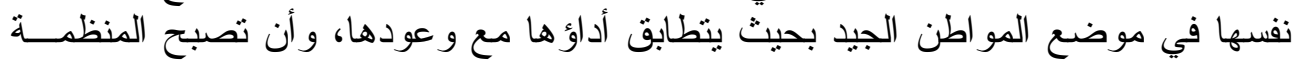

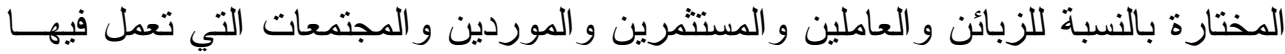




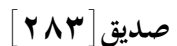

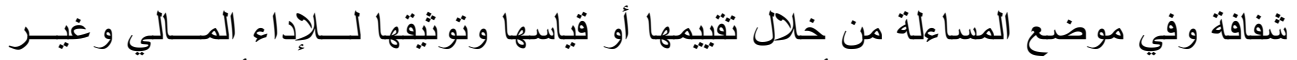

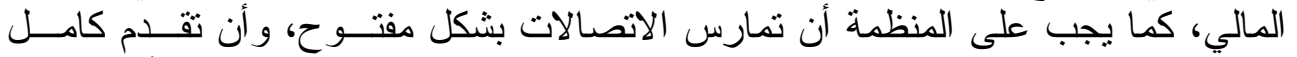

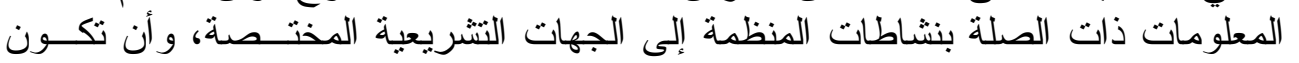

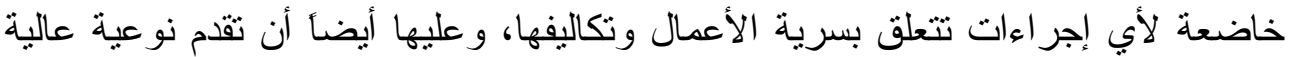

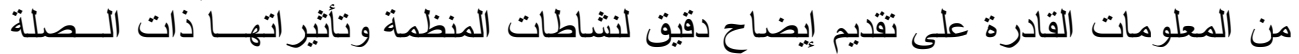

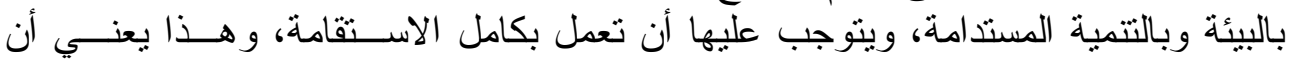

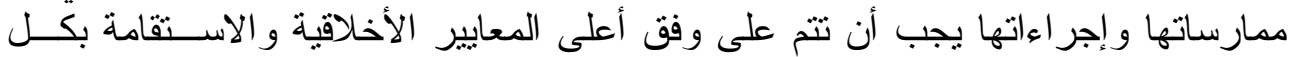

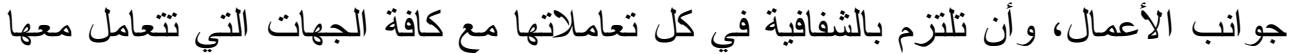
حكو مية و غير حكومية (Zadek and Merme, 2003, 19-20).

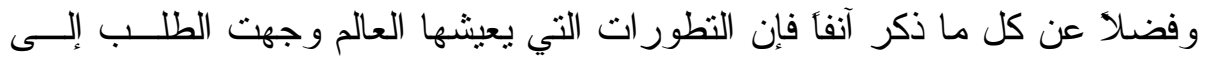

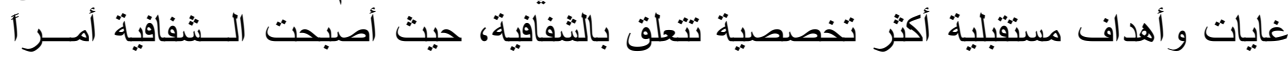

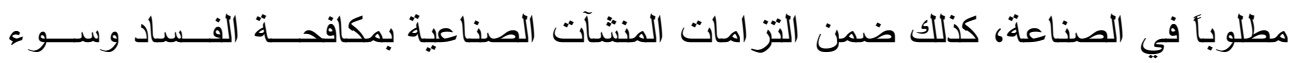
توزيع العو ائد، وكذلك تحقيق العدالة الاجتماعية من خلال المدفو عات المقدمة للحكومسات

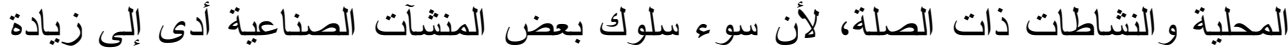

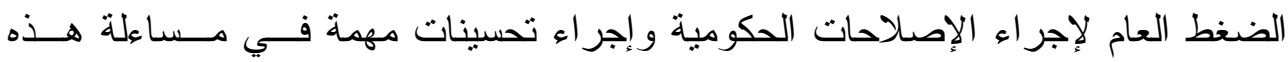

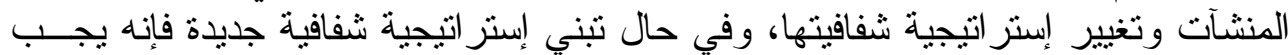

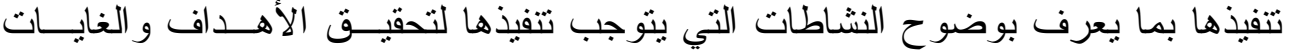

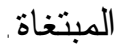

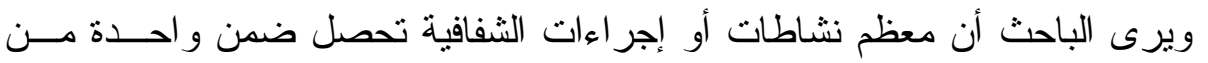

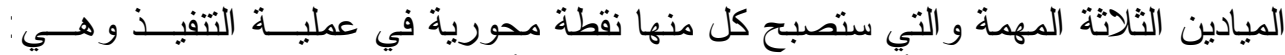

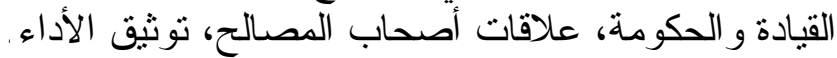

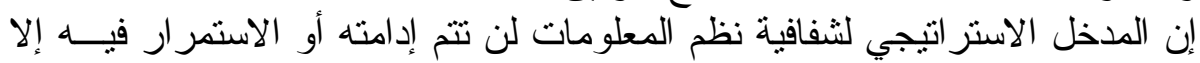

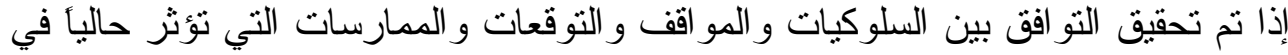

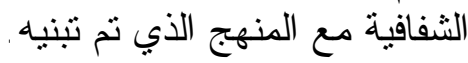

الاستتناجات و التوصيات

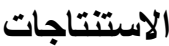

إن الثفافية هي مسار يوصل إلى الثقة العامة لذلك فإنه يمكن اعتبار الـشفافية فــي

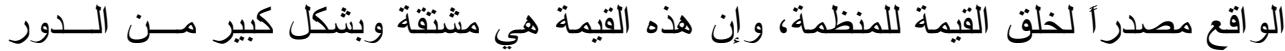

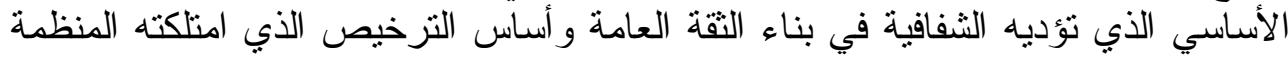

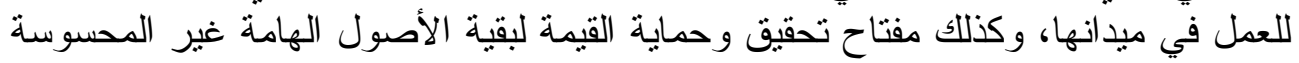

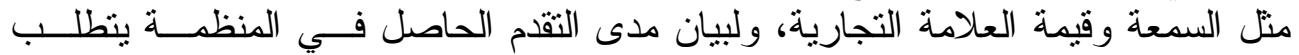

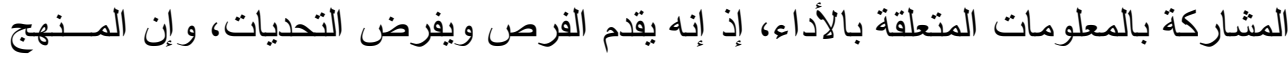

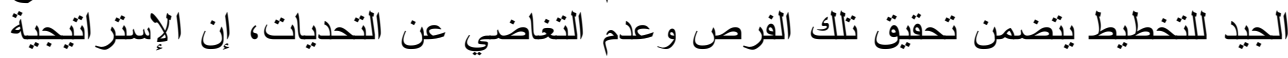

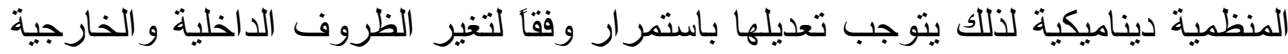

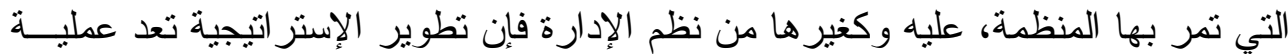

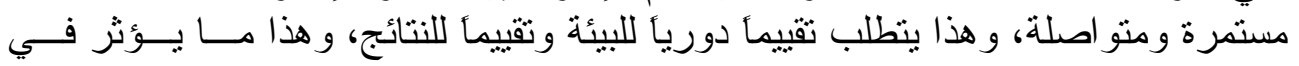
توصل البحث الى الإجابة عن الفرضية التي مضمونها: 


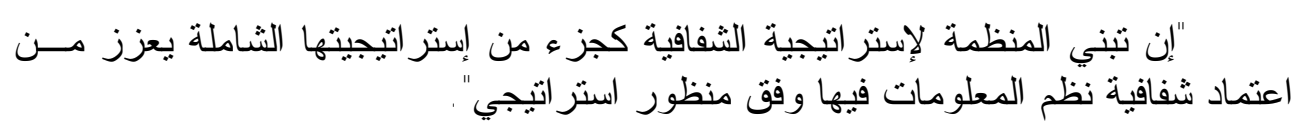

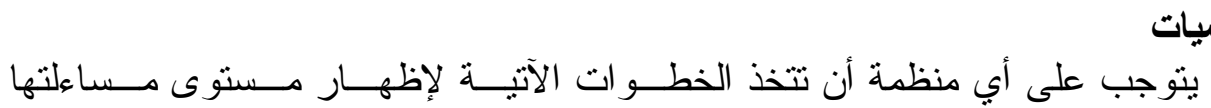

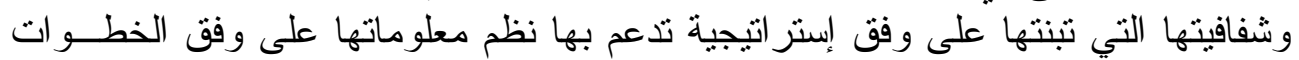

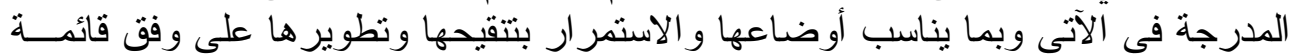

الفحص التي تطبقها.

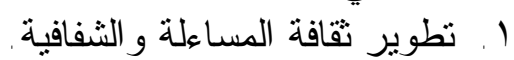

r. تبني بيان القيم ومجمو عة الأخلاقيات.

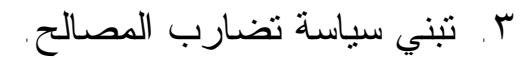

ع. . ضمان أن مدر اء مجالس الإدار ات يفهمون أنهم قادرون على تحمل مسؤولياتهم .

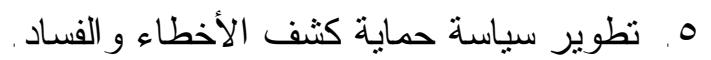

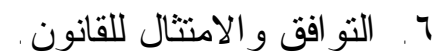

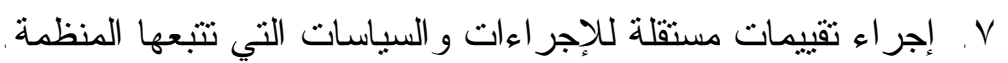

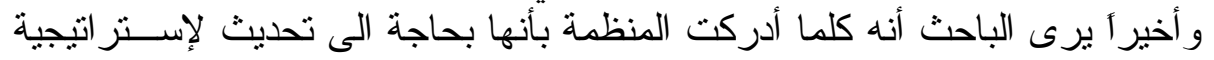

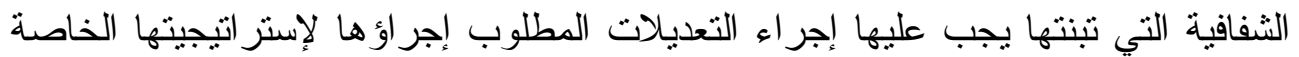

بالثفافية لغرض مو اكبة التغير ات الحاصلة في البيئة .

المراجع

1.Fung, Archon, Graham, Mary and Weil. David, 2003, The Political Economy of Transparency: What Makes Disclosure Policies Sustamable? Havverd University.

2. Gelos, R.Gaston and Wei, Shang-Jin , 2003, Transparency and International Investor behavior .

3. GEMI. 2004, Clear Advantage: Building Share holder Value, Environment: Value to the Investor .

4. Kochan and Rubenstein, 2000, "Toward a Stake holder Theory of the Firm: The Saturn Partnership", Organizational Science.

5. Post, J.E., L.E. Preston, and S.Sachs, 2002, Redefining the Corporation: Stakeholder Management and Organizational wealth. Stanford University Press.

6. Ronald B.Mrrchell, 1998, Sources of Transparency: Information Systems in International Regimes, University of Oregon .

7. Taraca, Ann, 2001, International convergence of Accounting Praetices: Choosing Between Iass and Us Gaap, University of New Sowth Wales .

8. Vishwanath, TRa , and Kaufmann , Daniel , 1999, Towards Transparency in Finance and

Governance, The world Bank

9.Zadek, S., and M.Merme, 2003, Redefining Materiality . Account ability. 